\title{
Monitor Accelerometer Running Based Android for Short Distance Runner
}

\author{
Andry Akhiruyanto ${ }^{1}$, Soegiyanto ${ }^{2}$, Sulaiman $^{3}$, Rumini $^{4}$ \\ \{aakhiruyanto@yahoo.co.id ${ }^{1}$, soegiyanto.ks@mail.unnes.ac.id ${ }^{2}$, sulaiman@mail.unnes.ac.id ${ }^{3}$, \\ rumini@mai.unnes.ac.id $\left.{ }^{4}\right\}$
}

Department of Physical Education, Faculty of Sport Science, Universitas Negeri Semarang

\begin{abstract}
The speed measuring instrument that is widely used in running activities is still a stopwatch that can only measure the time needed to travel a certain distance. Even though speed and number of steps are important components in short distance running. This study aims to produce a product design of speed monitoring and the number of steps of short distance running using an Android-based accelerometer. This study uses a qualitative approach, the main data obtained through observation, questionnaires, interviews and documentation. The procedure of research and development used is the Borg and Gall model. The results of the study show that the accelerometer on android can send data and be processed by programs that have been created by displaying information on the speed and number of steps. In conclusion, the Running Monitor product design based on android can be used to monitor the speed and number of steps of a short distance run
\end{abstract}

Keywords: Running Monitor, Android, Speed and Number of steps

\section{Introduction}

The lack of achievements obtained by Indonesia in athletic sports, especially the number of sprint runs, of course, needs improvement and efforts to develop the process based on science and technology [1]. Sprint run is influenced by one very important factor, namely the speed component. Speed is the ability to move or move from the body or limbs from one point to another or to work on the same repetitive activity continuously and in the shortest possible time [2], [3]. Mechanically, running speed can be defined as a product of the number of steps and the length of the step [4], [5].

Speed as a component of physical condition that is very important now its measurement has used sophisticated technological tools. For example sensors mounted on athletic shoes (Foot Pod, Polar and Suunt), Global Positioning System (GPS) and Global Positioning System (DGPS). besides that there are also radar, photo finish, kinematic analysis, photocells and optojump (OJ) which are usually used to measure speed when running [6], [7]. All of these tools were made to diagnose, evaluate and analyze the performance of athletes for increased performance [8].

The importance of the characteristics of short distance running such as speed and number of steps requires a measuring instrument that can accurately display the information needed. The problems that occur in the measurement of running speed are still using my battery and manual speed by using a stopwatch. The use of the stopwatch is a problem in the accuracy of the data taken because of the time difference in the keystrokes. So that it can cause a lot of errors 
(human error) because the reflex rate and human sensitivity vary, so there needs to be a system of automatic timing and runner tools [7], [8].

Seeing the various conditions of the results of the needs analysis, of course, it is necessary to increase the development of athletic sports, especially the more innovative short distance running numbers, especially the running speed training process so that they can optimize the role and function of the trainer. Sports science and technology innovation especially in short distance number athletics researchers will develop an Android Operating System (OS) based Running Monitor tool to determine the characteristics of short distance running, where the system has been used on Mobile (HP) and on the system one of them has been accelerometer plant that can be used to measure speed. The emergence of mobile phones and smartphones designed with the Android operating system, has helped the emergence of many applications in all areas, one of them in sports [9]. the use of accelerometers to measure human movement is becoming increasingly popular. The accelerometer measures acceleration in one to three orthogonal, vertical, anteroposterior, and Medio-lateral planes. They are generally used to analyze impacts, and are used in the analysis of various professional sports, one of which is track and field [10], [11].

Based on the introduction above, this study aims: To produce a product development design running an android application based monitor to determine the speed and number of steps of short distance running with low cost, accurate and reliable and useful in triggering academics to remain concerned about developments especially in the field of sports and is the latest innovations in conventional Stopwatches are more effective and efficient when used for training.

\section{Methods}

This study uses a qualitative approach. The main data is obtained through observation, questionnaires, interviews and documentation. The research and development procedure used is the Borg and Gall model, with 10 steps, namely: 1) Research and information collecting, 2) Planning, 3) Develop preliminary form of product, 4) Preliminary field testing, 5) Operational field testing, 6) Operational product revision, 7) Main field testing, 8) Main product revision, 9) Final product revision, 10) Dissemination and implementation [12], [13].

\section{Results and Discussion}

\subsection{Product Model}

Product images from the results of research and development of Android-based Running Monitor Accelerometers to determine the speed and number of short distance running steps are as follows: 


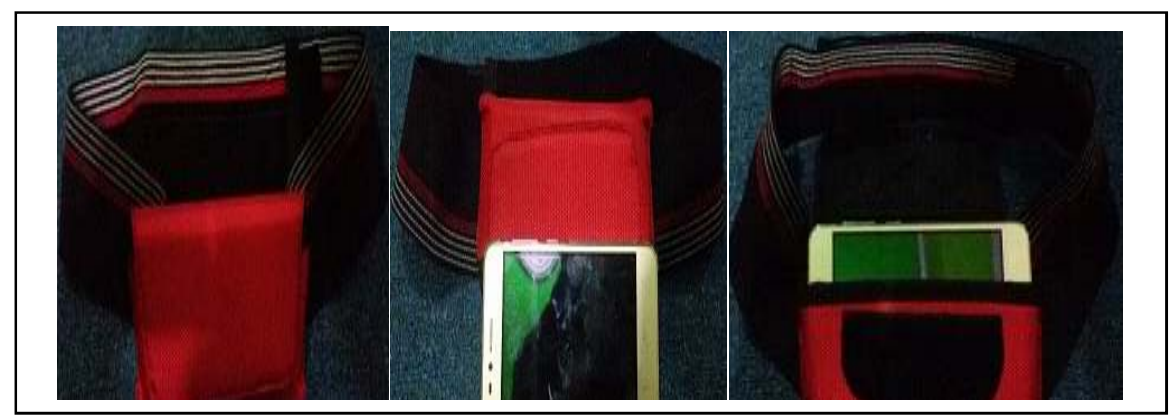

Figure.1. Accelerometer Running Monitor Product

This product is called Running Monitor based on Android is a system that aims to determine the speed and number of steps runners especially on short distance runs. The ability of an Android-based Running Monitor is 1.) Able to know in real time the speed and number of steps, 2) able to bring up speed data and the number of steps in the form of graphs and numerical data.

At the model development stage expert validation is carried out by assessing the feasibility of the model by involving experts/experts from academics or practitioners with the results:

Table 1. Results of Expert Validation

\begin{tabular}{ll}
\hline \multicolumn{1}{c}{ Aspect } & \multicolumn{1}{c}{ Assessment Indicator } \\
\hline Originality Aspect & $\begin{array}{l}\text { Research products have advantages in aspects of } \\
\text { originality } \\
\text { Research products have superior advantages in terms of } \\
\text { innovative work, materials, operations and maintenance } \\
\text { Innovation }\end{array}$ \\
Benefit Aspect & $\begin{array}{l}\text { The research product has a high usability advantage for a } \\
\text { wide audience in supporting efforts to foster athletic } \\
\text { sports in particular short distance running numbers }\end{array}$ \\
Environmental aspects & $\begin{array}{l}\text { Research products have the advantages of simplicity in } \\
\text { terms of structure, ease of operation }\end{array}$ \\
Safety and comfort aspects & $\begin{array}{l}\text { Research products have the advantage of the athlete's } \\
\text { level of safety and comfort during training } \\
\text { The research product has the advantage of manual usage } \\
\text { descriptions }\end{array}$ \\
\hline
\end{tabular}

1) Product Testing

The system was tested on runners to find out the results of the implementation of devices and applications on Android and Personal Computers (PC). 


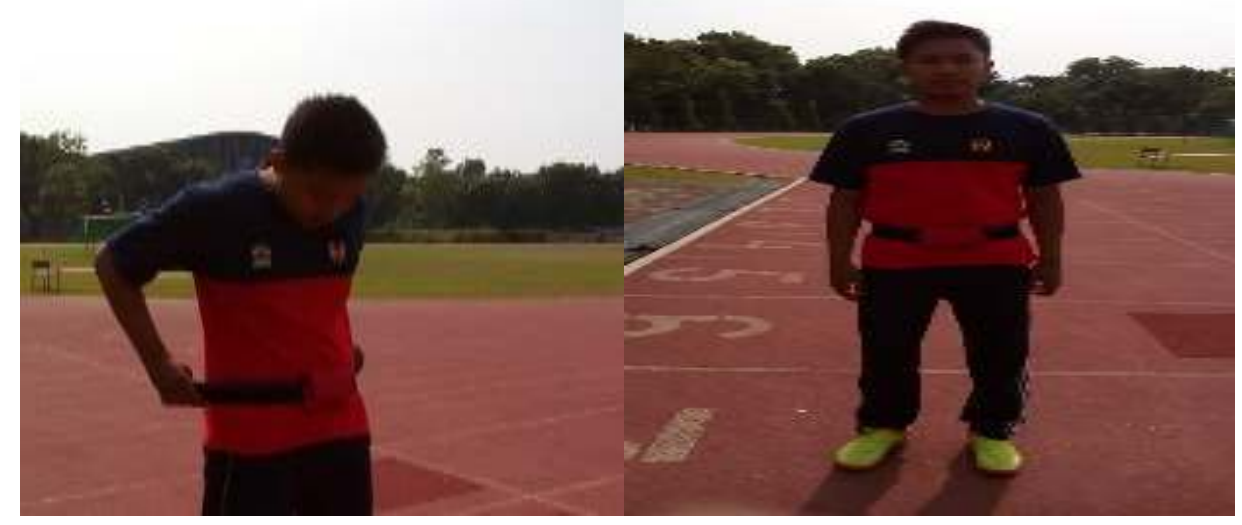

Figure.2. Runners get ready to wear a smartphone belt

Before running, the athlete performs preparations for filling in data and application settings on Android and presses "START" then prepares to run as.

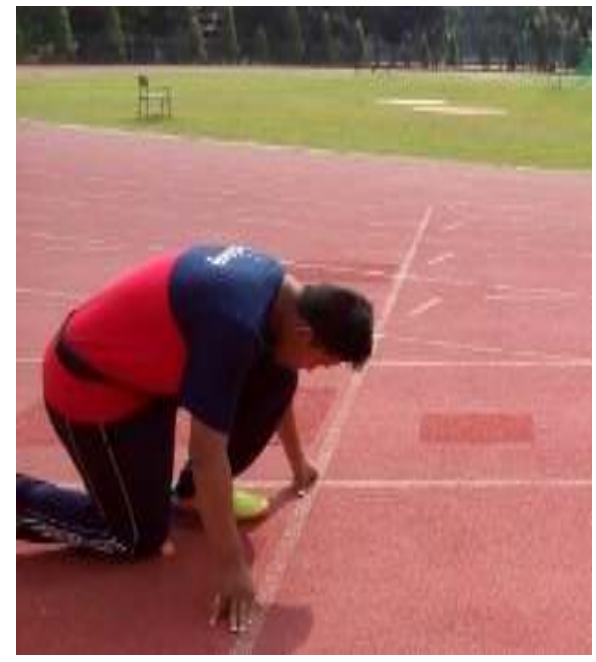

Figure. 3. Runners press the "START" button and prepare to run

During the preparation the android application will count down five seconds, marked with a "beep" every count. When the last count a long beep will be heard and the athlete starts running. 


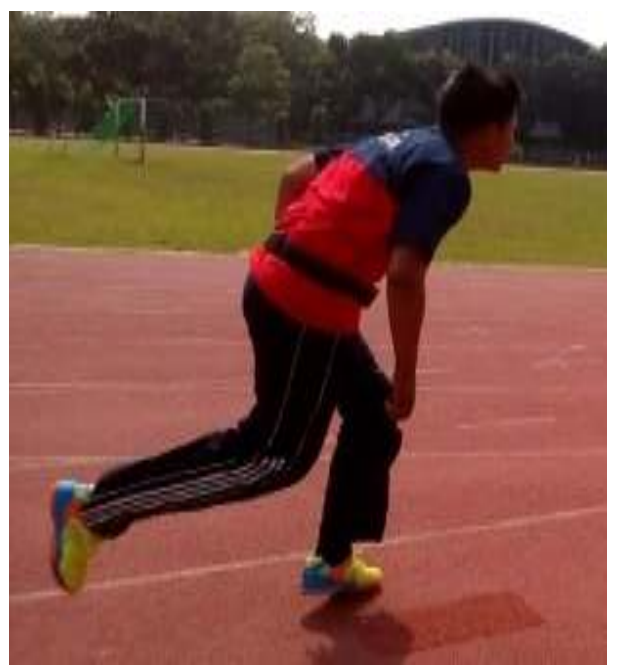

Fig. 4. Athletes run while using a belt with a smartphone

\section{2) Applications on Android}

The result of implementing the application to use an accelerometer sensor on Android will appear with the application name being "running".

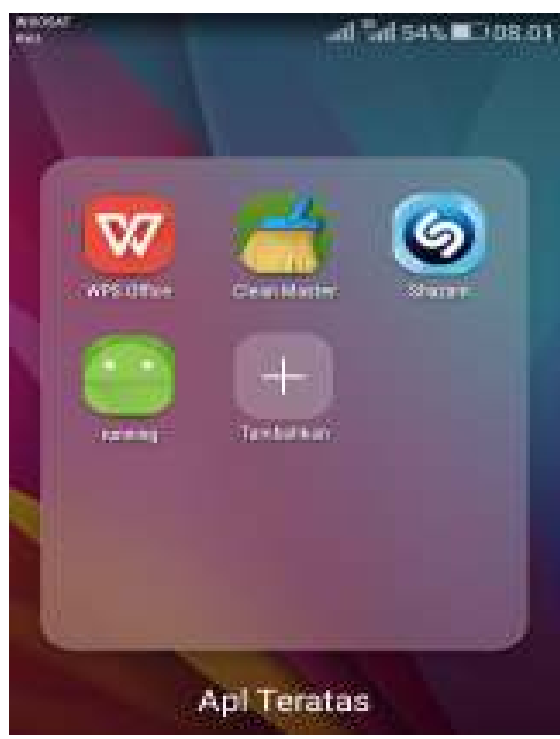

Figure.5. Initial App "running" application

When the application "running" is run it will appear like Figure 6. Before starting to run, the athlete must fill in the name and data age first, when the "+" button is pressed. This name and age data will not affect the system and its application but only for the name to be easily stored. When the data is filled in, click "ADD". 


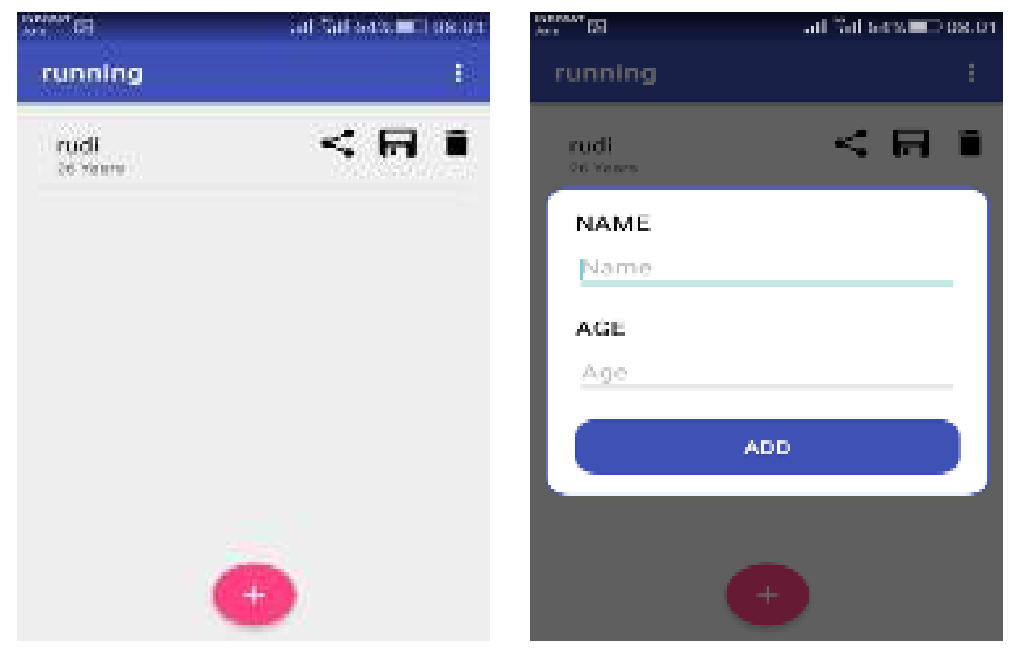

Figure. 6. Display Application "running" When Filling Data

After the "ADD" button is clicked, the "START" button will appear which indicates the application is ready to start. When the "START" button is clicked, the application will count down five seconds, marked with a "beep" every count. When the last count a long beep will be heard and the athlete starts running.

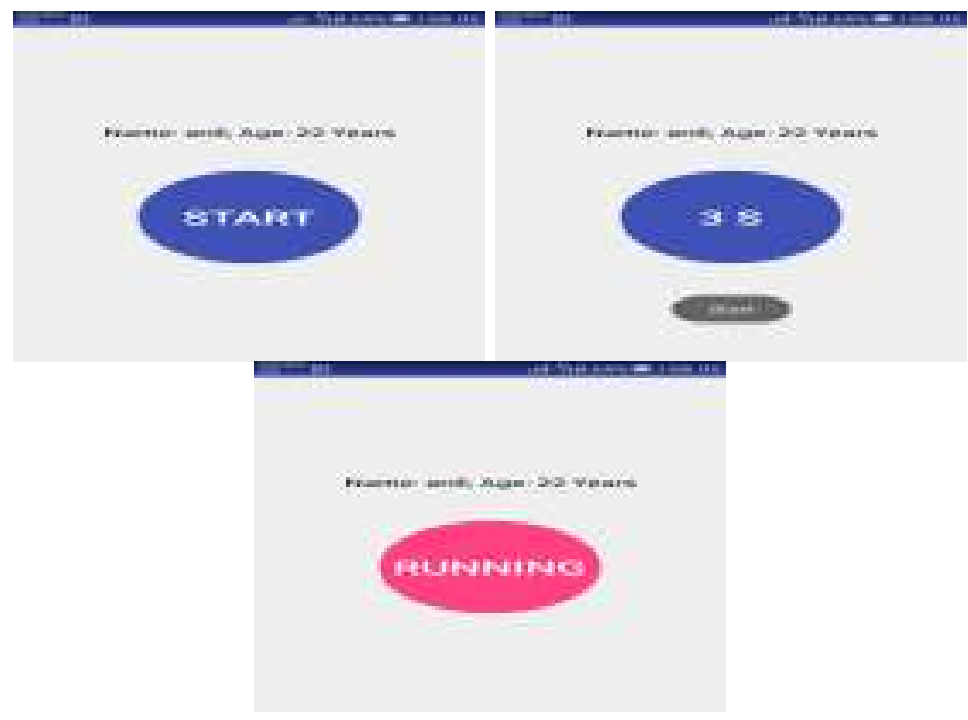

Figure. 7. Application "running when starting and running

Then the data that has been obtained is stored in the memory card or memory of the phone and then sent to the PC via USB and processed to determine the characteristics of acceleration, speed and distance of the runner. 


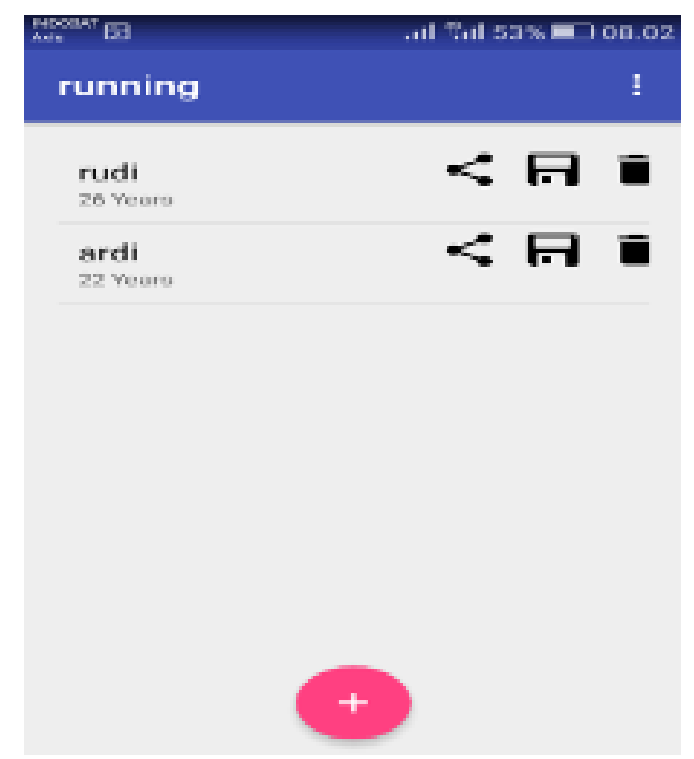

Figure. 8. The application "running" stores runner data

3) Applications on Personal Computers

After the athlete runs and the application on Android saves the results of the running data, connect the smartphone to the $\mathrm{PC}$ and run the application counter program and estimate the speed, speed and distance.

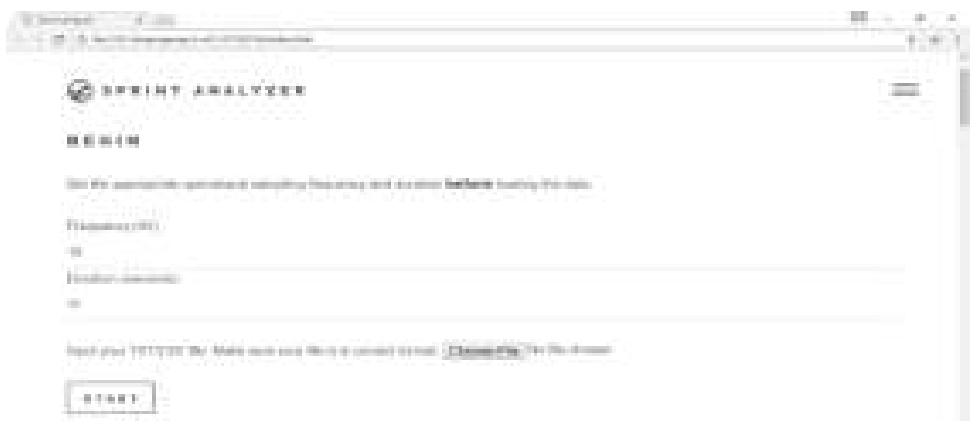

Figure.9. Initial display of the "sprint analyzer" data processing application

Set the duration to 15 seconds. Select the delivery file from the smartphone data from the athlete's test results when running, then click start, the display will appear as shown below. 


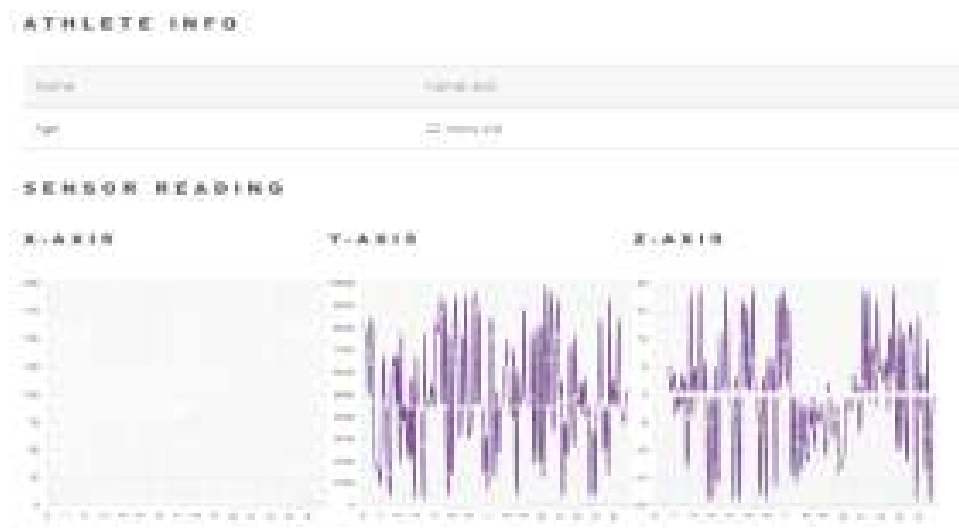

Figure. 10. The athlete's running acceleration graph on all three axes

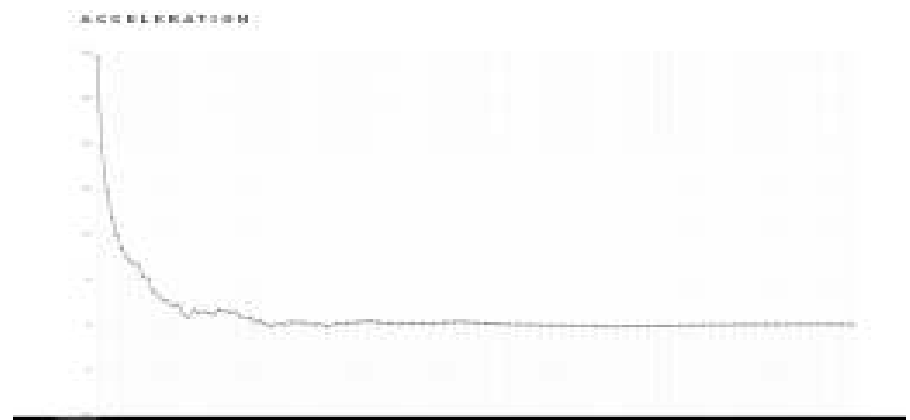

Figure. 11. The athlete's running acceleration graph for time

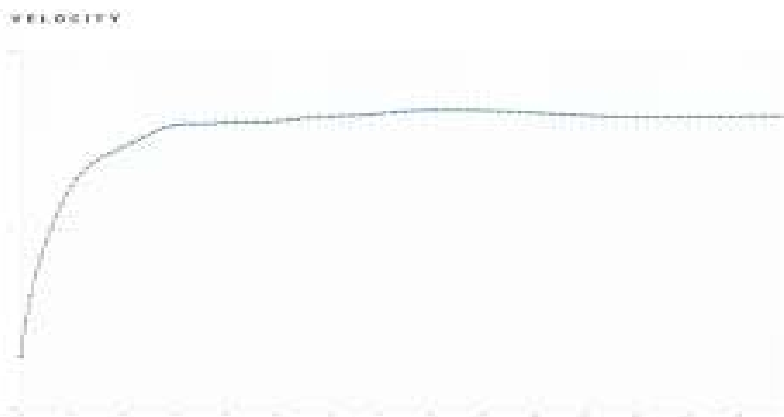

Fig. 12. Graph of athlete's running speed against time

Product feasibility assessments from experts at an average score of 85.75 which fall into the category of assessment "very good". This means that the product of the ball launcher that was developed was a very good or appropriate development and suitable for use in short distance running exercises. 


\section{Conclusion}

The product design of speed monitors and the number of steps of short distance running using an Android-based accelerometer have been successfully implemented. Accelerometer products running Android-based monitors can be used in short distance running exercises and are also effective in increasing the results of short-distance running exercises. 


\section{References}

[1] M. Jannah, "Kontribusi Metode Neuro-Linguistic Programming Terhadap Kemampuan Goal Setting Pelari Cepat Perorangan,” J. Psikol. Teor. dan Terap., vol. 3, no. 1, p. 42, 2012.

[2] A. Julfikar, "Pengaruh Latihan Lompat Kijang Terhadap Kecepatan Lari," JSSF (Journal Sport Sci. Fitness), vol. 1, no. 1, 2012.

[3] N. W. Kusnanik and L. M. Y. Isnaini, "The Effects Of Single Leg Hop Progression And Double Legs Hop Progression Exercise To Increase Speed And Explosive Power Of Leg Muscle.," Sport Mont, no. 43-45, pp. 70-74, 2015.

[4] R. J. Corn and D. Knudson, "Effect of elastic-cord towing on the kinematics of the acceleration phase of sprinting," J. Strength Cond. Res., vol. 17, no. 1, pp. 72-75, 2003.

[5] E. Bergamini, "Biomechanics of sprint running: a methodological contribution To cite this version: HAL Id: pastel-00591130 Biomechanics of sprint running: a methodological contribution," 2011.

[6] A. Dolenec and M. Čoh, "Comparison Of Photocell And Optojump Measurements Of Maximum Running Velocity," Kinesiol. Slov., vol. 15, no. 2, pp. 16-24, 2009.

[7] M. Schmidt, C. Rheinländer, K. F. Nolte, S. Wille, N. Wehn, and T. Jaitner, "IMUbased Determination of Stance Duration during Sprinting," Procedia Eng., vol. 147, pp. 747-752, 2016.

[8] C. Cummins, R. Orr, H. O’Connor, and C. West, "Global positioning systems (GPS) and microtechnology sensors in team sports: A systematic review," Sports Medicine, vol. 43, no. 10. pp. 1025-1042, 2013.

[9] M. E. Villapol, H. Jansen, A. Morales, J. Flores, H. Rodrigues, and M. Huerta, "Recording, storing and querying judo match data using an Android tool and Cloud computing," Proc. Inst. Mech. Eng. Part P J. Sport. Eng. Technol., vol. 231, no. 4, pp. 243-252, 2017.

[10] T. Tamura, "Application of accelerometers in physiological monitoring - a review," in Accelerometers: Principles, Structure and Applications, 2013.

[11] C. J. B. Kenneally-Dabrowski, B. G. Serpell, and W. Spratford, "Are accelerometers a valid tool for measuring overground sprinting symmetry?,” Int. J. Sport. Sci. Coach., vol. 13 , no. 2 , pp. 270-277, 2018.

[12] J. W. Creswell, Educational research: Planning, conducting, and evaluating quantitative and qualitative research, vol. 4. 2012.

[13] C. for E. R. and Innovation, Educational Research and Innovation Beyond Textbooks Digital Learning Resources as Systemic Innovation in the Nordic Countries, vol. 2009, no. 25. 2009. 